\title{
Disease Response or Clinical Classification Ongoing
}

National Cancer Institute

\section{Source}

National Cancer Institute. Disease Response or Clinical Classification Ongoing. NCI

Thesaurus. Code C162327.

An indication or description that assessment of disease response or clinical classification

of the disease is continuing. 